Aim of special session A presentation of hazards and health problems in mining and the possibilities for prevention with improved Occupational Safety and Health in small- and largescale mining worldwide.

Presenters: ${ }^{1}$ Erik Jørs, ${ }^{2}$ Muchtaruddin Mansyur, ${ }^{3}$ Liem J Fuk, ${ }^{4}$ Stephane Hallé, ${ }^{5}$ Cas J Badenhorst, ${ }^{6}$ Helmut Ehnes

${ }^{1}$ Department of Occupational and Environmental Medicine, Odense University Hospital, Odense, Denmark.

${ }^{2}$ Universitas Indonesia - Faculty of Medicine, Department of Community Medicine, Jakarta, Indonesia

${ }^{3}$ Prodia Occupational Health Institute International, Jakarta, Indonesia

${ }^{4}$ Ecole de technologie supérieure, Montreal, Canada

${ }^{5}$ Anglo American plc., Johannesburg, South Africa

${ }^{6}$ International Section of the ISSA Mining on Prevention in the Mining Industry, Bochum, Germany

\section{6a INTRODUCTION TO MINING HAZARDS AND GOOD PRACTICES IN FORMAL AND INFORMAL MINING}

E Jørs. Department of Occupational and Environmental Medicine, Odense University Hospital, Odense, Denmark

\subsection{6/oemed-2018-ICOHabstracts.696}

Mining is among the most hazardous workplaces at a global level. Accidents as well as pneumoconiosis, poisonings and cancers take a high dead toll among miners. Other diseases due to heavy workload, noise, vibrations and high or low temperature such as hearing loss, white fingers, carpal tunnel syndrome and muscle and back pain are not deadly but still serious for the miners. In this session we will be presented for miner's liver and kidney diseases, which might have a connexion to the high temperatures, dehydration and salt depletion in mines as also described in some farmers studies from Central America. Implementation of OHS preventive measures in mining is often difficult due to the mostly unregulated small scale and artisanal mining taking place in mainly low-income countries were rules and regulations are hard to enforce. Some key issues in prevention is appropriate laws and their enforcement, banning of toxic mining processes, better environmental control and education and new technology such as cooling wests used for prevention of heat distress among others.

\section{6b MINING WORKERS, ADMINISTRATIVE TASK, OBESITY, HYPERTRIGLYCERIDEMIA, AND YOUNG WORKERS INCREASED RISK LIVER FUNCTION ELEVATION AMONG INDONESIAN MALE WORKERS}

\footnotetext{
${ }^{1} \mathrm{M}$ Mansyur*, ${ }^{2} \mathrm{JF}$ Liem. 'Universitas Indonesia - Faculty of Medicine, Department of Community Medicine, Jakarta, Indonesia; ${ }^{2}$ Prodia Occupational Health Institute International, Jakarta, Indonesia
}

\subsection{6/oemed-2018-ICOHabstracts.697}

Introduction Mining workers have potential risks to be exposed by many toxicants. Due to the majority of toxicants metabolised through the liver this may be high risk of the liver function alteration due to occupational and non-occupational health hazards exposures. The purpose of this study was to explore the risk of mining worker to have liver function elevation (LFE) adjusted by other risk factors.

Methods A comparative cross sectional study was conducted to examine the secondary data of 2016 annual medical examination results of 5634 workers from six various industries in Indonesia. The data subjects consisted of 447 of those who had a LFE compared with 1341 subjects were randomly chosen from those data whose were normal in liver function enzyme. Liver function elevations were considered on the basis of serum aspartate aminotransferase and/or alanine aminotransferase level more than 5 points above reference levels. The risk of mining workers to have liver function elevation were calculated using Odds Ratios and adjusted by Type of Task, Chemical Exposure History, Age, Body Mass Index, Medical History and Triglyceride Level.

Result This study analysed 1781 male workers (31.0 \pm 7.4 year). No significant associations were observed between outcome and medical history of diabetes mellitus and liver disease as well as alcohol consumption, smoking, physical exercise, and chemical exposure history. Risk factors associated with LFE were identified including obesity (OR 4.0, 95\% CI: 3.1 to 5.0 ), work in mining sector (OR 2.0, 95\% CI: 1.6 to 2.6), role as administrative worker (OR 1.4, 95\% CI: 1.0 to 1.8 ), age $<35$ years (OR 1.4, 95\% CI: 1.1 to 1.9 ), and hypertriglyceridemia (OR 1.6, 95\% CI: 1.3 to 2.1 ) respectively.

Discussion Attributed risk factors of LFE among worker were identified including occupational, individual and modifiable metabolic risk. Further research is needed to explain the role of occupational exposures in LFE among miners.

\section{6c MINING WORKERS, OBESITY, KIDNEY DISEASE HISTORY, AND HYPERTENSION INCREASED RISK IMPAIRED KIDNEY FUNCTION AMONG INDONESIAN WORKERS}

${ }^{1} \mathrm{JF}$ Liem*, ${ }^{2} \mathrm{M}$ Mansyur. ${ }^{1}$ Prodia Occupational Health Institute International, Jakarta, Indonesia; '2Universitas Indonesia - Faculty of Medicine, Department of Community Medicine, Jakarta, Indonesia

\subsection{6/oemed-2018-ICOHabstracts.698}

Introduction Kidney Disease is a major health problem among productive age group. The purpose of this study was to explore the risk of mining worker to have Impaired Kidney Function.

Methods A comparative cross sectional study was conducted to examine the secondary data of 2016 annual medical examination results of 5634 workers from six various industries in Indonesia. The data subjects consisted of 90 of them who were considered Impaired Kidney Function (IKF) compared with 450 data subjects were randomly chosen from those who were normal serum creatinine. Those who have serum creatinine (SCr) level $>1.2 \mathrm{mg} / \mathrm{dL}$ and $>0.9 \mathrm{mg} / \mathrm{dL}$ for male and female respectively were categorised as IKF. Logistic regression analysis was used and the risk of mining workers to have IKF were calculated using Odds Ratios and adjusted by individual risk factors (age, hypertension, obesity, history of diabetes, history of kidney disease) as well as with occupational risk factors (type of task, chemical exposure, and heat exposure).

Result This study analysed 540 workers (32.4 years +8.5$)$. No significant associations were observed between outcome and medical history of diabetes mellitus, alcohol consumption, smoking, physical exercise, as well as chemical exposure history. Risk factors associated with IKF were identified including work in mining sector (OR 6.4, 95\% CI: 4.0 to 10.3), obesity (OR 2.5, 95\% CI: 1.5 to 4.0), grade II hypertension (OR 3.8, 95\% CI: 1.1 to 13.2), history of kidney disease (OR 9.7, 